\title{
Correction to: Data Analytics: Paving the Way to Sustainable Urban Mobility
}

\author{
Eftihia G. Nathanail and Ioannis D. Karakikes
}

\section{Correction to:}

\section{E. G. Nathanail and I. D. Karakikes (Eds.): \\ Data Analytics: Paving the Way to Sustainable Urban Mobility, AISC 879, https://doi.org/10.1007/978-3-030-02305-8}

The original version of the book was inadvertently published with: an incorrect spelling of the author affiliation in chapter 48 and incorrect spelling of the last name of the author Livia Mannini in chapter 16, in the table of contents and in the author index. The corrected book has been updated with the changes.

The updated version of these chapters can be found at https://doi.org/10.1007/978-3-030-02305-8_16

https://doi.org/10.1007/978-3-030-02305-8_48

https://doi.org/10.1007/978-3-030-02305-8

(C) Springer Nature Switzerland AG 2019

E. G. Nathanail and I. D. Karakikes (Eds.): CSUM 2018, AISC 879, p. C2, 2019.

https://doi.org/10.1007/978-3-030-02305-8_105 